\title{
Phase I clinical study of RG7356, an anti-CD44 humanized antibody, in patients with acute myeloid leukemia
}

\author{
Norbert Vey ${ }^{1,2}$, Jacques Delaunay ${ }^{3}$, Giovanni Martinelli ${ }^{4}$, Walter Fiedler ${ }^{5}$, Emmanuel \\ Raffoux ${ }^{6}$, Thomas Prebet ${ }^{1}$, Carlos Gomez-Roca ${ }^{7,8}$, Cristina Papayannidis ${ }^{4}$, Maxim \\ Kebenko ${ }^{5}$, Peter Paschka ${ }^{9}$, Randolph Christen ${ }^{10}$, Ernesto Guarin ${ }^{11}$, Ann-Marie \\ Bröske $^{12}$, Monika Baehner ${ }^{12}$, Michael Brewster ${ }^{13}$, Antje-Christine Walz ${ }^{11}$, Francesca \\ Michielin ${ }^{11}$, Valeria Runza ${ }^{12}$, Valerie Meresse ${ }^{11}$, Christian Recher ${ }^{7,14}$ \\ ${ }^{1}$ Institut Paoli-Calmettes, Marseille, France \\ ${ }^{2}$ Aix Marseille Université, Marseille, France \\ ${ }^{3}$ Service d'Hématologie Clinique, Hôpital Hôtel-Dieu, Nantes, France \\ ${ }^{4}$ Department of Experimental, Diagnostic and Specialty Medicine, University of Bologna, Bologna, Italy \\ ${ }^{5}$ Department of Medicine II, University Medical Center Hamburg-Eppendorf, Hamburg, Germany \\ ${ }^{6}$ Hôpital Saint Louis, AP-HP, EA3518 Université Paris VII, Paris, France \\ ${ }^{7}$ Institut Universitaire du Cancer de Toulouse Oncopole, Toulouse, France \\ ${ }^{8}$ Institut Claudius Regaud, Clinical Research Unit, Toulouse, France \\ ${ }^{9}$ Department of Internal Medicine III, University Hospital UIm, UIm, Germany \\ ${ }^{10}$ Product Development, Safety Risk Management, Roche, Basel, Switzerland \\ ${ }^{11}$ Pharma Research \& Early Development, Roche Innovation Center Basel, Basel, Switzerland \\ ${ }^{12}$ Pharma Research \& Early Development, Roche Innovation Center Penzberg, Penzberg, Germany \\ ${ }^{13}$ Pharma Research \& Early Development, Roche Innovation Centre, Welwyn, UK \\ ${ }^{14} \mathrm{CHU}$ de Toulouse, Université Toulouse III, Toulouse, France \\ Correspondence to: Norbert Vey, email: veyn@ipc.unicancer.fr \\ Keywords: RG7356, relapsed/refractory acute myeloid leukemia, anti-CD44 humanized antibody, phase I trial, cell adhesion \\ Received: January 20, $2016 \quad$ Accepted: March 28, 2016 \\ Published: April 11, 2016
}

\section{ABSTRACT}

RG7356, a recombinant anti-CD44 immunoglobulin G1 humanized monoclonal antibody, inhibits cell adhesion and has been associated with macrophage activation in preclinical models. We report results of a phase I dose-escalation study of RG7356 in relapsed/refractory acute myeloid leukemia (AML).

Eligible patients with refractory $A M L$, relapsed $A M L$ after induction chemotherapy, or previously untreated AML not eligible for intensive chemotherapy were enrolled and received intravenous RG7356 at dosages $\leq \mathbf{2 4 0 0}$ mg every other week or $\leq \mathbf{1 2 0 0} \mathbf{~ m g}$ weekly or twice weekly; dose escalation started at $\mathbf{3 0 0} \mathbf{~ m g}$.

Forty-four patients (median age, 69 years) were enrolled. One dose-limiting toxicity occurred (grade 3 hemolysis exacerbation) after one $1200 \mathrm{mg}$ dose (twice-weekly cohort). The majority of adverse events were mild/moderate. Infusion-related reactions occurred in $64 \%$ of patients mainly during cycle 1 . Two patients experienced grade 3 drug-induced aseptic meningitis. Pharmacokinetics increased supraproportionally, suggesting a target-mediated drug disposition (TMDD) at $\geq 1200 \mathrm{mg}$. Two patients achieved complete response with incomplete platelet recovery or partial response, respectively. One patient had stable disease with hematologic improvement.

RG7356 was generally safe and well tolerated. Maximum tolerated dose was not reached, but saturation of TMDD was achieved. The recommended dose for future AML evaluations is $\mathbf{2 4 0 0} \mathbf{~ m g}$ every other week. 


\section{INTRODUCTION}

Acute myeloid leukemia (AML) is the most common form of acute leukemia in adults, and its incidence increases with age. With intensive chemotherapy regimens, complete remission rates between $70 \%$ and $80 \%$ can be achieved [1,2]; however, the majority of patients relapse and prognosis is very poor [3]. Treatment options are even more limited in elderly patients because of the high frequency of chemotherapy-resistant forms of AML $[2,4]$, combined with the inability of the majority of these patients to tolerate intensive treatments [5]. Thus, there is a need to develop new therapies with more effective mechanisms of action and lower toxicity as compared with conventional chemotherapy.

CD44 is an adhesion molecule expressed on hematopoietic precursors, including long-term cultureinitiating cells, colony forming unit-granulocyte macrophages, and leukemic cells [6]. Its main ligand is hyaluronic acid (HA), an extracellular matrix glycosaminoglycan present in the bone marrow (BM) microenvironment. Interactions between CD44 and HA are essential to mediate the cellular adhesion and migration of leukemic stem cells (LSC) to the stroma in the BM [7]. Consequently, administration of anti-CD44 monoclonal antibodies $(\mathrm{mAb})$ was associated with eradication of LSC after serial transplants in immunocompromised murine models of AML [8]. In addition, signal transduction by CD44 regulates many cellular functions, including myeloid differentiation [9].

The investigational drug RG7356 is a recombinant immunoglobulin G1 (IgG1) humanized $\mathrm{mAb}$ that specifically binds to the standard region of CD44 near the HA binding domain. By blocking the interaction between CD44 and HA, RG7356 inhibits cell adhesion to HA-coated plates at nanomolar concentrations in vitro [10]. In vitro, the RG7356-mediated disruption of the tumor microenvironment triggers the release of specific chemo-attractants (e.g. CCL2) that recruit and activate macrophages, leading to the phagocytosis of RG7356opsonized tumor cells (Roche internal data).

Taken together, these data along with the known CD44 biology and its role in leukemia supported the rationale for clinical investigation of RG7356. We report the results of a phase I dose-escalation study of RG7356 in patients with refractory/relapsed AML.

\section{RESULTS}

\section{Patient characteristics}

Forty-four patients were evaluable (Table 1). Half of the patients were $\geq 69$ years of age. Thirty-seven patients $(84 \%)$ had refractory or relapsed disease, including 11 $(25 \%)$ that had a previous transplant. Seven patients
$(16 \%)$ were previously untreated elderly patients unfit for conventional chemotherapy. Twelve out of 43 patients (28\%) had unfavorable cytogenetics, and 11 out of 37 (30\%) had FLT3 mutations. All 42 patients with available pretreatment BM biopsy were positive for CD44 expression on leukemic blasts by immunohistochemistry (IHC).

\section{Safety and tolerability}

RG7356 was investigated at 4 dose levels and 3 schedules (every other week, weekly, or twice weekly) (Table 2). Median treatment duration was 23 days (range, $1-269$ days), and 10 patients (23\%) were treated for $\geq 60$ days.

Eighteen patients were not evaluable for doselimiting toxicity (DLT) determination, owing to disease progression prior to day $21(n=9)$, early event of aseptic meningitis $(n=2)$, infusion-related reactions (IRRs) $(n=1)$, incomplete dose on day $1(n=2)$, not allowed concomitant medication $(n=1)$, early death due to unrelated fatal pulmonary infection event $(n=1)$, and withdrawn consent $(n=2)$. Only 1 DLT was observed - a grade 3 hemolysis exacerbation occurring after 1 dose of $1200 \mathrm{mg}$ twice weekly. This patient had AML secondary to myelodysplastic syndrome (MDS) with a history of long-lasting red blood cell (RBC) transfusion dependence. Transfusion needs had increased regularly in the weeks preceding RG7356 treatment, concurrently with several episodes of transient increase of unconjugated bilirubin and appearance of alloreactive anti-RhD antibodies. The baseline hemoglobin level was $9.5 \mathrm{~g} / \mathrm{dL}$, total bilirubin was $42.3 \mu \mathrm{mol} / \mathrm{L}$, and lactate dehydrogenase (LDH) was $134 \mathrm{IU} / \mathrm{L}$. One hour after the end of RG7356 administration, the patient presented with unconjugated bilirubin increase $(80.4 \mu \mathrm{mol} / \mathrm{L})$ and severe anemia (hemoglobin level, $6.8 \mathrm{~g} / \mathrm{dL}$ ), although LDH level remained unchanged (137 IU/L). Direct and indirect Coombs tests were positive, and no other markers of hemolysis were present. Although not confirmed, a relationship to RG7356 could not be ruled out.

Because CD44 is normally expressed on human erythrocytes [11], we performed a systematic assessment of direct and indirect Coombs tests in 23 patients. All patients were closely observed for signs of hemolysis. Indirect Coombs test was negative at baseline in all patients for which a screening or pre-dose value was obtained $(n=20)$ and was positive in 15 out of 18 patients $(83 \%)$ tested after the infusion of cycle 1. Direct Coombs test was positive at baseline in 5 out of 21 patients (24\%), and was positive in 16 out of 18 patients (89\%) tested after the infusion of cycle 1 . No other cases of hemolysis were recorded, including in patients with positive Coombs tests. No evidence of increase in transfusion dependency was observed during the study and across the different cohorts.

The majority of treatment-related adverse events (AEs) were transient and mild to moderate in severity (Table 3). The most frequent treatment-related AEs were 
Table 1: Patient characteristics

\begin{tabular}{|c|c|}
\hline Characteristic & $\begin{array}{c}\text { Number of patients (\%) } \\
n=44\end{array}$ \\
\hline Median age (range), years & $69(20-82)$ \\
\hline$\leq 60$ & $15(34)$ \\
\hline$>60$ & $29(66)$ \\
\hline Sex (male/female) & $26 / 18$ \\
\hline \multicolumn{2}{|l|}{ ECOG performance status at screening } \\
\hline 0 & $18(41)$ \\
\hline 1 & $21(48)$ \\
\hline 2 & $5(11)$ \\
\hline \multicolumn{2}{|l|}{ FAB classification } \\
\hline M0 & 4 \\
\hline M1-2 & 22 \\
\hline M4-5 & 7 \\
\hline M6 & 3 \\
\hline sAML & 7 \\
\hline Undifferentiated AML & 1 \\
\hline \multicolumn{2}{|l|}{ Cytogenetics } \\
\hline Number evaluable & $43(98)$ \\
\hline Intermediate risk & $31(72)$ \\
\hline Normal karyotype & $24(56)$ \\
\hline Other & $7(16)$ \\
\hline Unfavorable risk & $12(28)$ \\
\hline Complex & $6(14)$ \\
\hline Other & $6(14)$ \\
\hline FLT3 mutations & $11 / 37(30)$ \\
\hline ITD & 6/37 (16) \\
\hline TKD & $5 / 37(14)$ \\
\hline NPM1 mutations & $8 / 34(24)$ \\
\hline \multicolumn{2}{|l|}{ Status } \\
\hline Relapsed/refractory after $\geq 2$ lines & $5(11)$ \\
\hline Relapsed/refractory after 1 line & $21(48)$ \\
\hline Post-transplant relapse & $11(25)$ \\
\hline Previously untreated elderly & $7(16)$ \\
\hline Median interval from diagnosis to study enrollment (range), months & $13(0.9-130)$ \\
\hline
\end{tabular}

Abbreviations: AML, acute myeloid leukemia; ECOG, Eastern Cooperative Oncology Group; FAB, French-AmericanBritish; ITD, internal tandem duplication; sAML, secondary acute myeloid leukemia; TKD, tyrosine kinase domain. Patients were classified into favorable, intermediate, or unfavorable risk groups based on cytogenetics and/or molecular abnormalities. Percentages are calculated on number with evaluable cytogenetics. 
Table 2: Dose escalation, dose-limiting toxicities, and response

\begin{tabular}{lccccc}
\hline Dose & Schedule & Number of patients & $\begin{array}{c}\text { Number of DLT- } \\
\text { evaluable patients }^{\text {a }}\end{array}$ & DLTs & Response \\
\hline $300 \mathrm{mg}$ & $\mathrm{q} 2 \mathrm{w}$ & 4 & 3 & 0 & 0 \\
$600 \mathrm{mg}$ & $\mathrm{q} 2 \mathrm{w}$ & 5 & 3 & 0 & $1 \mathrm{CRp}, 1 \mathrm{PR}$ \\
$1200 \mathrm{mg}$ & $\mathrm{q} 2 \mathrm{w}$ & 7 & 4 & 0 & 0 \\
$2400 \mathrm{mg}$ & $\mathrm{q} 2 \mathrm{w}$ & 5 & 5 & 0 & 0 \\
$1200 \mathrm{mg}$ & Weekly & 9 & 3 & 0 & $1 \mathrm{HI}$ \\
$600 \mathrm{mg}$ & Twice & 4 & 3 & 1 \\
$1200 \mathrm{mg}$ & weekly & Twice & 10 & 5 & 0 \\
\hline
\end{tabular}

Abbreviations: CRp, complete response with incomplete platelet recovery; DLT, dose-limiting toxicity; HI, hematologic improvement; MTD, maximum tolerated dose; PR, partial response; PK, pharmacokinetics.

${ }^{a}$ Evaluable patient is defined as any treated patient who previously had a DLT and/or completed the DLT period without having a subsequent DLT.

${ }^{\mathrm{b}}$ At study termination, only one DLT occurred in this cohort out of the 5 evaluable patients; no additional patients were included and the MTD was not determined.

Table 3: Drug-related AEs

\begin{tabular}{lcc}
\hline & \multicolumn{2}{c}{ Number of patients (\%) } \\
n= 44 & Grade $\geq 3$ \\
Drug-related event & Any grade & $10(23)$ \\
Any & $39(89)$ & 13 \\
Total number of AEs & 151 & 0 \\
Infusion-related reactions & $28(64)$ & 0 \\
Pyrexia & $14(32)$ & 0 \\
Headache & $7(16)$ & 0 \\
Coombs indirect test positive & $4(9)$ & $2(5)$ \\
Asthenia & $4(9)$ & 0 \\
Nausea & $4(9)$ & $2(5)$ \\
Increased alanine aminotransferase & $3(7)$ & 0 \\
Vomiting & $3(7)$ & 0 \\
Abdominal pain & $2(5)$ & $1(2)$ \\
Increased blood bilirubin & $2(5)$ & 0 \\
Decreased appetite & $2(5)$ & 0 \\
Fatigue & $2(5)$ & 0 \\
Constipation & $2(5)$ & 0 \\
Rash & $2(5)$ & $2(5)$ \\
Aseptic meningitis & $2(5)$ & \\
\hline
\end{tabular}

Abbreviation: AE, adverse event.

Included are drug-related AEs that occurred in at least 2 patients. The other related AEs of grade $\geq 3$ were increased blood lactate dehydrogenase, febrile neutropenia, hemolysis, neutropenia, tumor lysis syndrome, and decreased white blood cell count experienced by 1 patient each $(2 \%)$. 
grade $1 / 2$ IRRs, the majority of which occurred during the first infusion (59\%) compared with subsequent cycles (16\%). Incidence of IRRs decreased from $75 \%$ to $54 \%$ after the slower infusion rate was implemented. There was no apparent correlation between dose, schedule, and incidence or severity of IRRs.

Two cases of drug-induced aseptic meningitis (DIAM) were reported early after a dosage of $1200 \mathrm{mg}$ weekly on cycle 1 , day 3 . Peak concentration $\left(\mathrm{C}_{\max }\right)$ in both patients was below the mean $\mathrm{C}_{\max }(369 \mu \mathrm{g} / \mathrm{ml})$ of the highest evaluated safe dose level $(2400 \mathrm{mg})$, and increases in blood cytokines were in the low range observed for other patients, indicating no dose relationship. In 1 patient, cerebrospinal fluid (CSF) concentration was $0.8 \%$ of concomitant RG7356 serum concentration. Although no baseline comparison was possible, we observed high CSF levels of interleukin-10 (IL-10), IL-1 receptor antagonist, macrophage inflammatory protein-1 alpha, macrophage inflammatory protein-1 beta (MIP-1 $\alpha$, MIP-1 $\beta$ ), IL-6, IL-8, and macrophage colony stimulating factor- 1 in this patient that were consistent with DIAM. Both patients recovered spontaneously within approximately 1 week, but were not rechallenged. No additional cases of DIAM and/or associated neurologic symptoms were recorded after intensification of steroid premedication (methylprednisolone $100 \mathrm{mg}$ was replaced by dexamethasone $20 \mathrm{mg}$ ). Maximum tolerated dose (MTD) was not reached for doses escalated up to 2400 mg every other week.

\section{Pharmacokinetics of RG7356}

The pharmacokinetic (PK) data for cycle 1 demonstrated that the time to peak concentration $\left(\mathrm{t}_{\max }\right)$ occurred shortly after the end of the infusion (3-6 hours) in all cohorts (Supplementary Table 1; Figure 1). For the every-other-week regimen, there was a supraproportional increase in mean exposure $\left(\mathrm{C}_{\max }\right.$ and area under the curve [AUC]) from the 300-mg to 1200-mg dose and less than dose proportional from $1200-\mathrm{mg}$ to $2400-\mathrm{mg}$ dose. Total clearance $(\mathrm{Cl})$ and volume of distribution $\left(\mathrm{V}_{\mathrm{d}}\right)$ were high (relative to other $\mathrm{IgG}$ antibodies) at $300 \mathrm{mg}$, declined with increasing dose, and plateaued at $1200 \mathrm{mg}$, at which point target-mediated drug disposition (TMDD) saturation occurred. A similar PK profile was observed following the weekly regimen at the same dose. Mean half-life $\left(t_{1 / 2}\right)$ was 2-3 days and remained the same over the entire dose range.

\section{Responses}

One complete response (CR) with incomplete platelet recovery $(\mathrm{CRp})$ and 1 partial response (PR) were recorded. The responders had received RG7356 $1200 \mathrm{mg}$ every other day, had normal cytogenetics, and no FLT3 or NPM1 mutations. One patient (CRp) was in second relapse following chemotherapy, while the other patient (PR) had previously untreated AML secondary to MDS. Durations of response were 81 and 154 days,

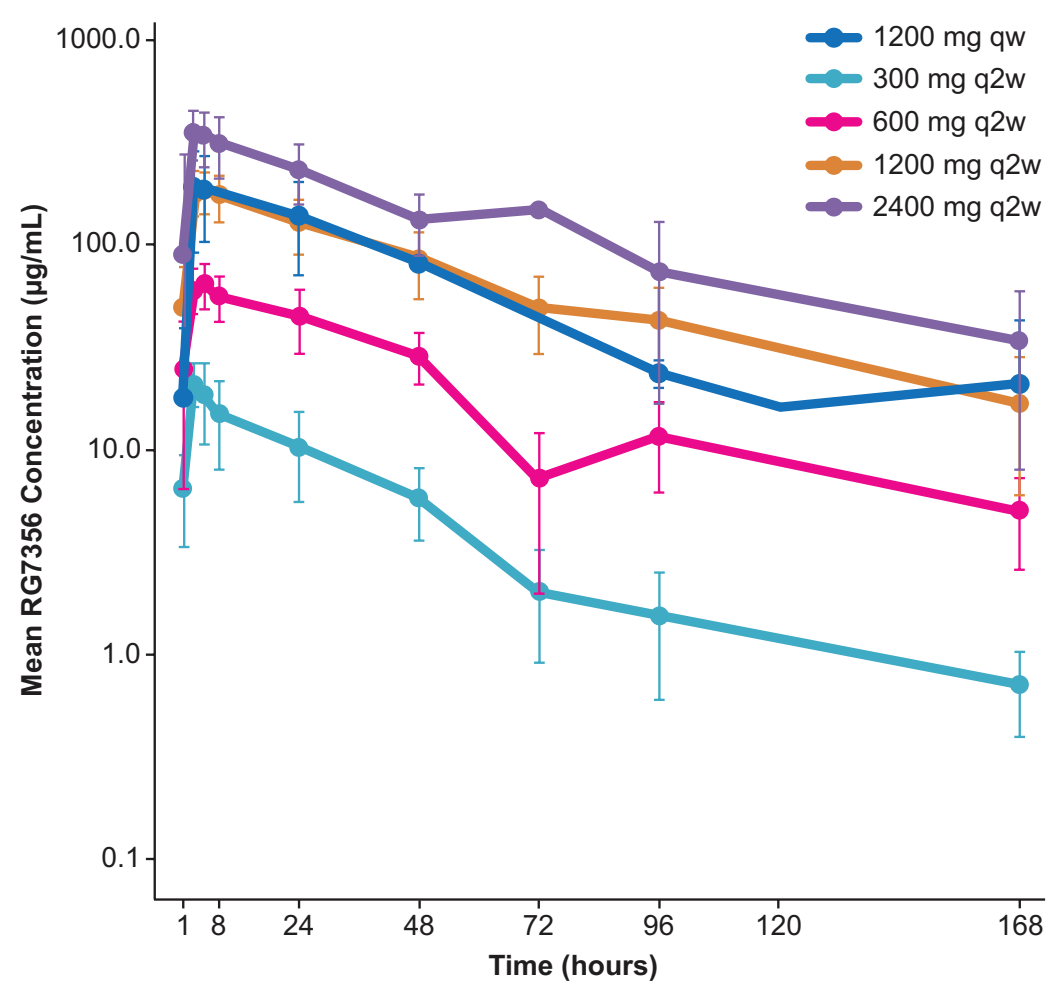

Figure 1: Mean RG7356 concentration for cycle 1.

Abbreviations: qw, weekly; q2w, every 2 weeks. 
respectively. One additional patient in the 600-mg everyother-day dose achieved stable disease with hematologic improvement (HI; neutrophil improvement according to 2006 International Working Group (IWG) Response Criteria in Myelodysplasia [12]) that lasted for 26 cycles (Figure 2). Disease control rate $(\mathrm{CR}+\mathrm{PR}+\mathrm{HI})$ was $7 \%$. The majority of patients progressed, including $25 \%$ who progressed during the first 2 cycles.

\section{Pharmacodynamics}

During treatment with RG7356, we observed a trend for increase of macrophages $\left(\mathrm{CD}^{+} 8^{+}\right)$and decrease of stem cell-like AML blasts (CD34 ${ }^{+}$) in BM biopsies (Figure 3), in agreement with preclinical data that suggested that the mechanism of action of RG7356 involves active macrophage recruitment and subsequent phagocytic activity against tumor cells (Roche internal data). There were no changes in the CD44 and HA expression pattern in BM (data not shown). One patient with stable disease and $\mathrm{HI}$ showed a decrease in $\mathrm{CD} 34^{+}$cells and an increase in $\mathrm{CD} 4^{-} / \mathrm{CD} 38^{+}$cells, suggesting blast differentiation (Figure 2).

\section{DISCUSSION}

Increased expression of different LSC markers has been associated with poor clinical outcome in patients with AML treated with conventional chemotherapy [13], and therefore, several of those cell surface antigens might serve as therapeutic targets, such as CD123, C-type lectin-like molecule 1 (CLL-1), CD47, T cell Ig mucin 3 (TIM-3), CD96, CXCR4, or CD33 [14-20]. For most of these targets, mAbs have indeed been developed but are still in preclinical or early clinical development. CD44 is a particularly attractive target in AML because its expression on leukemic blasts has been confirmed in $100 \%$ of 131 patients with various types of AML (F. HoffmannLa Roche Ltd, unpublished data). Furthermore, CD44 activation is capable of enhancing AML blast cell survival and resistance to apoptosis [21]. CD44 also plays a key role in LSC homing in the BM, and thus, disrupting the LSC niche is a promising therapeutic approach given the role played by these cells in the resistance to conventional chemotherapy [22]. Our preclinical data show that RG7356 can induce macrophage-mediated phagocytosis

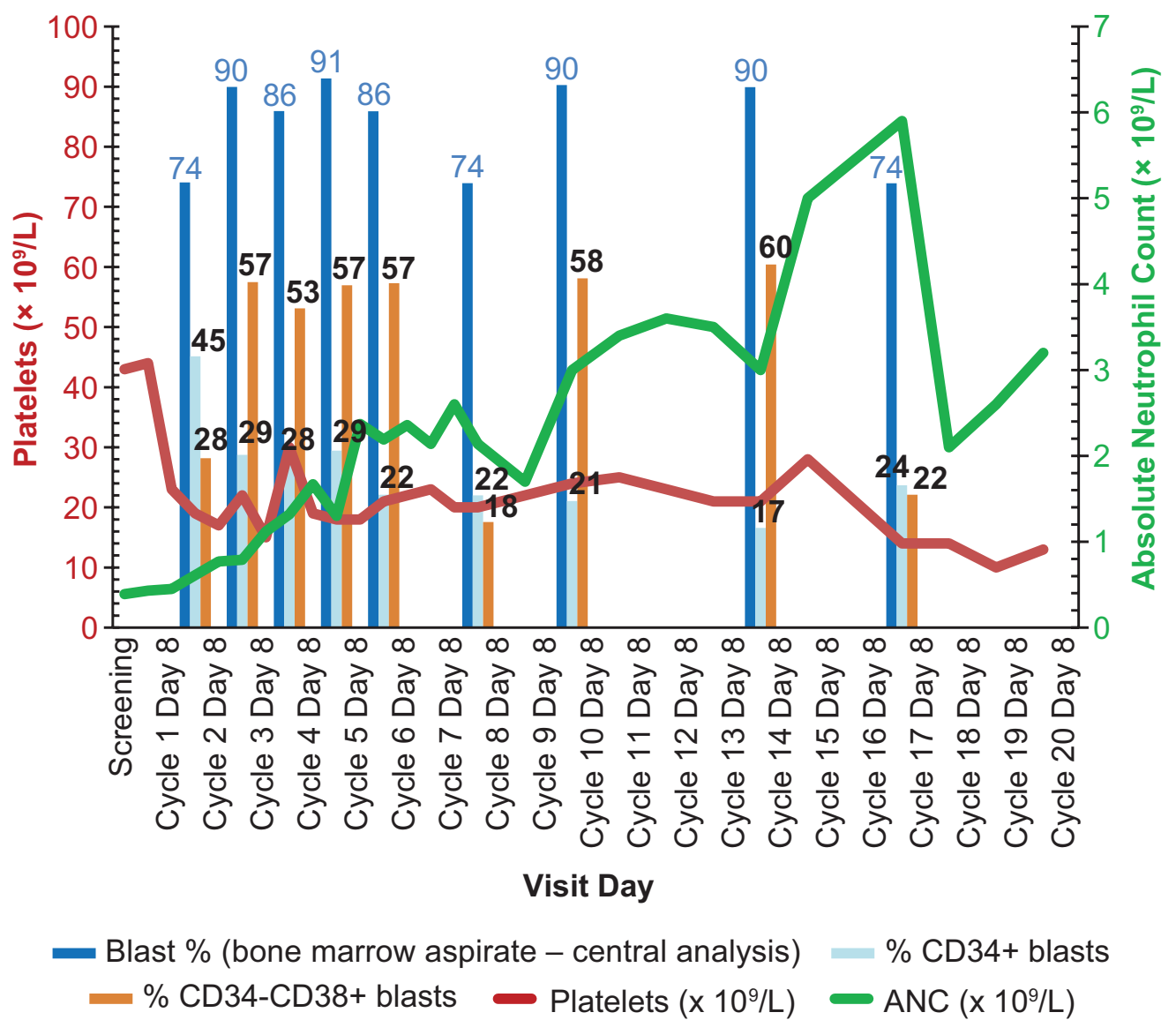

Figure 2: Leukemic stem cell (LSC) differentiation during treatment with RG7356. LSC differentiation during treatment with RG7356 (patient 3015, $600 \mathrm{mg}$, twice weekly dose regimen, on treatment for 26 cycles). LSC differentiation is shown by reduction of percentage of $\mathrm{CD} 34^{+}$blasts and percentage increase of $\mathrm{CD} 34^{-} / \mathrm{CD} 38^{+}$blasts in the bone marrow. Hematologic improvement (HI) is shown by absolute neutrophil count (ANC) increase (green line). 
of target cells in vitro, which may account for most of its direct antitumor activity (Roche internal data).

In this study, we have reported the first results of the administration of RG7356, an IgG1 anti-CD44 mAb, in patients with AML. Increased macrophage frequencies were observed on BM biopsy specimens, as measured by CD68 staining by IHC. Interestingly, this increase in macrophages was paralleled by a decreased frequency of $\mathrm{CD}_{3} 4^{+}$cells. In addition to this effect, 1 patient who achieved an $\mathrm{HI}$ had increased frequencies of $\mathrm{CD} 34^{-} / \mathrm{CD} 38^{+}$ cells together with a reduction in $\mathrm{CD} 34^{+}$cells, suggesting the induction of blast differentiation. This observation is consistent with previous in vitro studies that showed that anti-CD44 antibodies may trigger differentiation [23, 24].

The PK analysis indicated that the TMDD was more pronounced in patients with AML ( $\geq 1200 \mathrm{mg})$ compared with that observed in patients with solid tumors ( $\geq 450 \mathrm{mg}$ ) (Roche internal data). The PK differed from that expected for an IgG1 monoclonal antibody, with a large $\mathrm{V}_{\mathrm{d}}$, high total $\mathrm{Cl}$, and short $\mathrm{t}_{1 / 2}$ of $<4$ days, justifying the investigation of biweekly administration.

Overall, RG7356 administration was safe and well tolerated. Only 1 DLT was observed, and MTD was not reached at dosages up to $2400 \mathrm{mg}$ every other week. The most frequent AEs were moderate IRRs, which decreased substantially after premedication intensification. Indirect Coombs tests' positivity was observed in $83 \%$ of the tested patients following RG7356 administration; however, this was not associated with hemolysis, except in 1 patient who presented with hemolysis exacerbation after the first infusion. In toxicology studies (in vitro blood compatibility studies), RG7356 did not show any hemolytic potential (F. Hoffmann-La Roche Ltd, unpublished data). Based on these data, the risk of hemolysis following RG7356 administration seems minimal, but the occurrence of falsepositive immunohematologic tests has to be anticipated

\section{A. Macrophage accumulation}

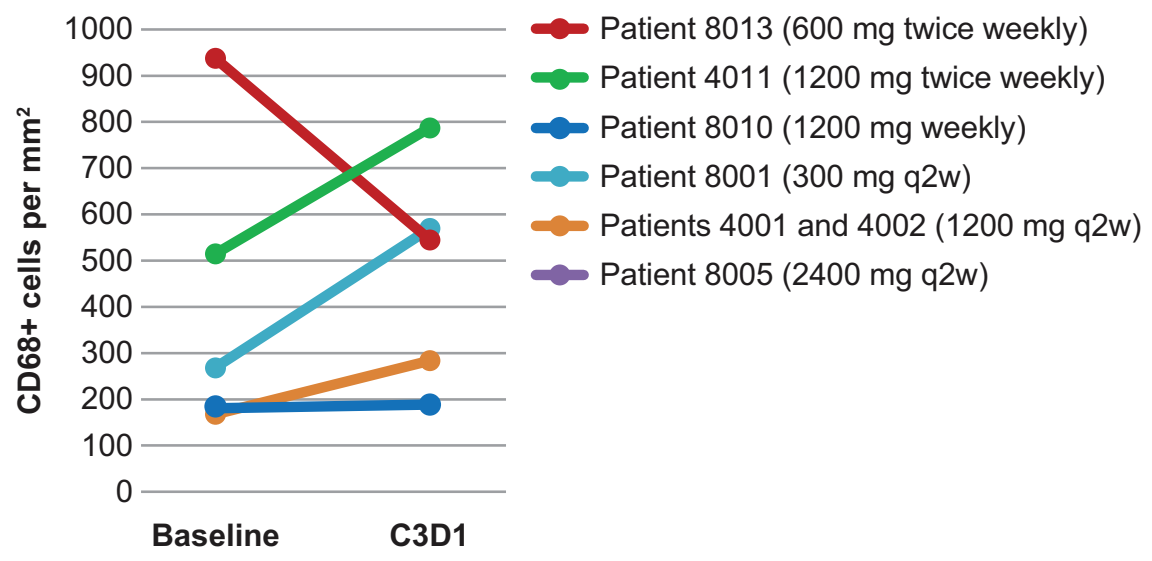

\section{B. Leukemic stem cell reduction}

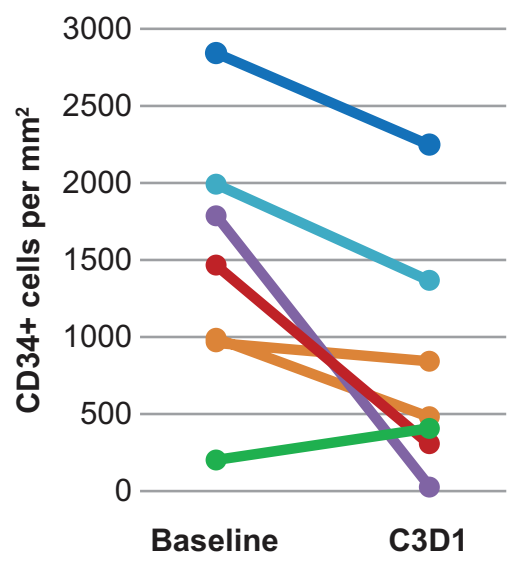

Figure 3: Macrophage and leukemic stem cell changes during treatment with RG7356. A. Macrophage (CD68) frequency and $\mathbf{B}$. leukemic stem cell $(\mathrm{CD} 34)$ reduction in the bone marrow was shown by immunohistochemistry analysis at baseline (pre-dose cycle 1 , day $1[\mathrm{C} 1 \mathrm{D} 1])$ and on treatment (pre-dose cycle 3, day 1 [C3D1]). 
for patients who may require $\mathrm{RBC}$ transfusions. This is explained by the high expression of CD44 on erythrocytes [25], which carries the Indian blood group system [26].

Two cases of DIAM were observed, both following the first infusion of RG7356. Recovery was achieved within a few days following steroid administration. As a consequence, premedication using dexamethasone was recommended by the protocol data safety monitoring group, and no additional cases were recorded precluding more extensive biologic analysis of suspected DIAM. DIAM is a rare complication observed following the administration of various drugs, such as nonsteroidal anti-inflammatory drugs, intrathecal chemotherapy, antiepileptic drugs, and immunomodulatory/antiinflammatory agents, including intravenous Igs or mAbs [27-29]. The pathophysiology of these 2 cases remains elusive, and may include direct interaction of RG7356 with meninges, induction of an inflammatory response, or hypersensitivity reactions. Recently, an increasing number of DIAM cases following the administration of various mAbs has been reported [30]. Overall, cases of DIAM are probably underreported, and attention should be paid to this rare complication in patients treated with mAbs.

Altogether, our data show that the administration of RG7356 doses able to saturate TMDD in a time- and concentration-dependent manner was safe. Limited clinical activity was seen with a disease control rate of $7 \%$ in a population of patients with advanced AML; 1 CRp, 1 PR, and 1 stable disease with HI that was associated with reduced $\mathrm{CD} 34^{+}$cells were reported. It is worth noting that the goal of an anti-CD44-specific approach in AML is to target the LSC compartment. In the context of this phase I trial, treatment activity was evaluated by the response rate, which was tailored to measure bulk tumor cell killing that did not necessarily reflect the effects on LSC. Indeed, demonstration of an effect on putative LSC in humans remains a challenge using classic response criteria [31].

In conclusion, the administration of RG7356 is safe at a recommended dose of 2400-mg every-otherweek, $1200 \mathrm{mg}$ weekly, or $600 \mathrm{mg}$ twice weekly. Based on the observed short $t_{1 / 2}$, a more frequent administration schedule (e.g. 3 times a week) might also be worth testing. The limited clinical activity seen here does not support the use of RG7356 as monotherapy on patients with florid AML; however, investigation in the context of minimal residual disease might represent a means to unravel selective effects on LSC. Furthermore, the lack of clinical activity but favorable toxicity profile of RG7356 as a monotherapy support the rationale for further investigation as a combination therapy with cytotoxic agents such as cytarabine or in another clinical setting, such as consolidation or maintenance therapy.

\section{MATERIALS AND METHODS}

\section{Patient selection}

Key inclusion/exclusion criteria are provided in the Supplemental Material. Briefly, patients were eligible if they were diagnosed with AML according to the World Health Organization's criteria, and provided signed written informed consent.

Patients were eligible regardless of CD44 expression. CD44 expression had previously been evaluated by IHC staining in a series of 131 trephine BM biopsies from patients with AML of all subtypes and stages of disease; all samples were CD44 ${ }^{+}$(F. HoffmannLa Roche Ltd, unpublished data). Patients were classified into favorable, intermediate, and unfavorable risk groups on the basis of cytogenetics and/or molecular abnormalities [32].

\section{Study design}

The study was conducted in 8 centers in France, Italy, and Germany following approval by each country's Institutional Review Board and registration on ClinicalTrials.gov (study identifier: NCT01641250), and was performed in accordance with the principles of the Declaration of Helsinki. Multiple doses and schedules of RG7356 were assessed with the aim of determining the MTD/optimal biologic dose (OBD). A standard " $3+$ 3 " design was used. Cohorts of at least 3 patients were enrolled in one of the RG7356 dosage levels administered consecutively on an every other week, weekly, or twice weekly schedule for each 14-day cycle.

The DLT period was defined as the first 21 study days following first administration. The definition of DLT is available in the Supplemental Material. Hypersensitivity reactions and IRRs were not considered dose-limiting.

In the absence of DLT, the RG7356 dose was escalated by $100 \%$ increments until MTD or OBD was reached. MTD was defined as the highest dose level below which at least 2 patients in a dose cohort experienced a DLT. The OBD was defined as the dose that demonstrated the maximum/optimal pharmacodynamic activity and PK properties.

\section{Treatment}

Based on the results of the phase I study in patients with $\mathrm{CD}^{+}$solid tumors (NCT01358903) (Roche internal data), the starting dose was defined as $300 \mathrm{mg}$ every other day. Flat doses were used. The RG7356 treatment schedule is provided in the Supplemental Material. Premedication consisting of acetaminophen, diphenhydramine, and corticoids (methylprednisolone 
replaced by dexamethasone in the course of the study) was mandatory for the first 2 infusions.

\section{Response and toxicity assessments}

BM aspirates were performed every 14 days provided that the patient remained in the study. IWG response criteria were used [33]. For patients showing no response, HI was defined as cytopenia improvements according to the 2006 IWG Response Criteria in Myelodysplasia [12]. All patients who received at least 1 dose of RG7356 were included for general safety or efficacy evaluations. Toxicity was evaluated using the National Cancer Institute Common Terminology Criteria for Adverse Events version 4.03.

\section{Pharmacokinetic assessments}

Samples were taken during cycle 1 on days $1,2,3$, and 8 and cycle 2 on day 1 . Estimation of the PK parameters were performed using standard noncompartmental (model independent) methods in cycle 1 . Actual sampling time was used to calculate PK parameters. In all calculations, 0 was substituted for concentrations below the quantification limit of the assay. Total clearance, $\mathrm{V}_{\mathrm{d}}, \mathrm{t}_{1 / 2}, \mathrm{t}_{\max }, \mathrm{C}_{\max }, \mathrm{AUC}$, individual and mean serum RG7356 concentrations versus time, and interpatient variability were assessed. To determine the influence of antigen expression on actual drug distribution and/or elimination, the TMDD was determined. The PK analysis was performed using Phoenix WinNonLin version 6.2.

\section{Pharmacodynamic assessments}

Whole blood was sampled to assess routine blast cell counts, circulating CD44 ${ }^{+}$leukemic blasts, and stem cell population by multicolor flow cytometry. In addition to routine AML markers on blasts, immunophenotyping included the assessment of circulating LSC (CD44, CD34, CD38, and/or additional markers), T cells (CD3, CD4, CD8), B cells (CD19), NK cells (CD3, CD16/56), and monocytes (CD14), and their respective CD44 expression levels.

Serial BM aspirates were collected for morphological routine assessments, CD44-expressing blast cell counts, and stem cell population assessment by multicolor flow cytometry. BM biopsy samples were collected at pre-dose cycle 1 , pre-dose cycle 3 , and at progression for routine assessments (cellularity, percent blasts) and for exploratory markers including CD44, HA, CD68, and CD34 assessment by IHC.

\section{ACKNOWLEDGMENTS}

The phase I clinical study (ClinicalTrials.gov Identifier NCT01641250) was sponsored by F. HoffmannLa Roche Ltd, Basel, Switzerland. The authors would like to thank the site and sponsor study management teams and the patients who agreed to participate in the study. Under the direction of the authors, editorial assistance was provided by Tara Beers Gibson, $\mathrm{PhD}$, of Envision Scientific Solutions, and funded by F. HoffmannLa Roche Ltd.

\section{CONFLICTS OF INTEREST}

N. Vey: Roche (honoraria); J. Delaunay: No conflicts to disclose; G. Martinelli: Speakers' bureau: Novartis, BMS, Celgene; Consultant: Ariad, Pfizer, Roche, MSD; W. Fiedler: Research funding: Pfizer Pharma $\mathrm{GmbH}$; Travel grants: Teva GmbH, Gilead Sciences $\mathrm{GmbH}$; E. Raffoux: No conflicts to disclose; T. Prebet: No conflicts to disclose; C. Gomez-Roca: No conflicts to disclose; C. Papayanndis: No conflicts to disclose; M. Kebenko: No conflicts to disclose; P. Paschka: No conflicts to disclose; C. Recher: Research funding: Amgen, Chugai, Novartis, Celgene; Advisory board: Celgene, Sunesis; R. Christen, E. Guarin, A-B. Bröske, M. Baehner, M. Brewster, A-C. Walz, F. Michielin, V. Runza, and V. Meresse are or have been employees of Roche.

\section{REFERENCES}

1. Burnett AK, Hills RK, Milligan DW, Goldstone AH, Prentice AG, McMullin MF, Duncombe A, Gibson B, Wheatley K. Attempts to optimize induction and consolidation treatment in acute myeloid leukemia: results of the MRC AML12 trial. Journal of Clinical Oncology. 2010; 28: 586-595. doi: 10.1200/JCO.2009.22.9088

2. Döhner H, Estey EH, Amadori S, Appelbaum FR, Büchner T, Burnett AK, Dombret H, Fenaux P, Grimwade D, Larson RA, Lo-Coco F, Naoe T, Niederwieser D, Ossenkoppele GJ, Sanz MA, Sierra J, et al. Diagnosis and management of acute myeloid leukemia in adults: recommendations from an international expert panel, on behalf of the European LeukemiaNet. Blood. 2010; 115: 453-474. doi: 10.1182/ blood-2009-07-235358

3. Breems DA, Van Putten WL, Huijgens PC, Ossenkoppele GJ, Verhoef GE, Verdonck LF, Vellenga E, De Greef GE, Jacky E, Van der Lelie J, Boogaerts MA, Löwenberg B. Prognostic index for adult patients with acute myeloid leukemia in first relapse. Journal of Clinical Oncology. 2005; 23:1969-1978. doi: 10.1200/JCO.2005.06.027

4. Büchner $T$, Berdel WE, Haferlach $C$, Haferlach $T$, Schnittger S, Müller-Tidow C, Braess J, Spiekermann K, Kienast J, Staib P, Grüneisen A, Kern W, Reichle A, Maschmeyer G, Aul C, Lengfelder E, et al. Age-related risk profile and chemotherapy dose response in acute myeloid leukemia: a study by the German Acute Myeloid Leukemia Cooperative Group. Journal of Clinical Oncology. 2009; 27 : 61-69. doi: 10.1200/JCO.2007.15.4245

5. Vey N. Targeting age-related changes in the biology of acute myeloid leukemia: is the patient seeing the 
progress? Interdiscip Top Gerontol. 2013; 38: 73-84. doi: $10.1159 / 000343623$

6. Ghaffari S, Dougherty GJ, Eaves AC, Eaves CJ. Altered patterns of CD44 epitope expression in human chronic and acute myeloid leukemia. Leukemia. 1996; 10: 1773-1781. doi: $10.4161 /$ cbt. 21784

7. Zhou L, Guo X, Jing BA, Zhao L. CD44 is involved in CXCL-12 induced acute myeloid leukemia HL-60 cell polarity. Biocell. 2010; 34: 91-94.

8. Jin L, Hope KJ, Zhai Q, Smadja-Joffe F, Dick JE. Targeting of CD44 eradicates human acute myeloid leukemic stem cells. Nat Med. 2006; 12: 1167-1174. doi: 10.1038/nm1483

9. Ponta H, Sherman L, Herrlich PA. CD44: from adhesion molecules to signalling regulators. Nat Rev Mol Cell Biol. 2003; 4:33-45. doi: 10.1038/nrm1004

10. Birzele F, Voss E, Nopora A, Honold K, Heil F, Lohmann S, Verheul H, Le Tourneau C, Delord JP, van Herpen C, Mahalingam D, Coveler AL, Meresse V, Weigand S, Runza V, Cannarile M. CD44 isoform status predicts response to treatment with anti-CD44 antibody in cancer patients. Clinical cancer research. 2015; 21: 2753-2762. doi: 10.1158/1078-0432.CCR-14-2141

11. Telen MJ, Udani M, Washington MK, Levesque MC, Lloyd E, Rao N. A blood group-related polymorphism of CD44 abolishes a hyaluronan-binding consensus sequence without preventing hyaluronan binding. J Biol Chem. 1996; 271: 7147-7153. doi: 10.1074/jbc.271.12.7147

12. Cheson BD, Greenberg PL, Bennett JM, Lowenberg B, Wijermans PW, Nimer SD, Pinto A, Beran M, de Witte TM, Stone RM, Mittelman M, Sanz GF, Gore SD, Schiffer CA, Kantarjian H. Clinical application and proposal for modification of the International Working Group (IWG) response criteria in myelodysplasia. Blood. 2006; 108: 419-425. doi: 10.1182/blood-2005-10-4149

13. Vergez F, Green AS, Tamburini J, Sarry JE, Gaillard B, Cornillet-Lefebvre P, Pannetier M, Neyret A, Chapuis N, Ifrah N, Dreyfus F, Manenti S, Demur C, Delabesse E, Lacombe C, Mayeux P, et al. High levels of CD34+CD38low/-CD123+ blasts are predictive of an adverse outcome in acute myeloid leukemia: a Groupe Ouest-Est des Leucemies Aigues et Maladies du Sang (GOELAMS) study. Haematologica. 2011; 96: 1792-1798. doi: 10.3324/haematol.2011.047894

14. He SZ, Busfield S, Ritchie DS, Hertzberg MS, Durrant $\mathrm{S}$, Lewis ID, Marlton P, McLachlan AJ, Kerridge I, Bradstock KF, Kennedy G, Boyd AW, Yeadon TM, Lopez AF, Ramshaw HS, Iland H, et al. A Phase 1 study of the safety, pharmacokinetics and anti-leukemic activity of the anti-CD123 monoclonal antibody CSL360 in relapsed, refractory or high-risk acute myeloid leukemia. Leukemia \& Lymphoma. 2015; 56: 1406-1415. doi: 10.3109/10428194.2014.956316

15. Bakker AB, van den Oudenrijn S, Bakker AQ, Feller N, van Meijer M, Bia JA, Jongeneelen MA, Visser TJ, Bijl
N, Geuijen CA, Marissen WE, Radosevic K, Throsby M, Schuurhuis GJ, Ossenkoppele GJ, de Kruif J, et al. C-type lectin-like molecule-1: a novel myeloid cell surface marker associated with acute myeloid leukemia. Cancer Res. 2004; 64: 8443-8450. doi: 10.1158/0008-5472.CAN-04-1659

16. Majeti R, Chao MP, Alizadeh AA, Pang WW, Jaiswal S, Gibbs KD, Jr., van Rooijen N, Weissman IL. CD47 is an adverse prognostic factor and therapeutic antibody target on human acute myeloid leukemia stem cells. Cell. 2009; 138: 286-299. doi: 10.1016/j.cell.2009.05.045

17. Jan M, Chao MP, Cha AC, Alizadeh AA, Gentles AJ, Weissman IL, Majeti R. Prospective separation of normal and leukemic stem cells based on differential expression of TIM3, a human acute myeloid leukemia stem cell marker. Proceedings of the National Academy of Sciences of the United States of America. 2011; 108: 5009-5014. doi: 10.1073/pnas. 1100551108

18. Hosen N, Park CY, Tatsumi N, Oji Y, Sugiyama H, Gramatzki M, Krensky AM, Weissman IL. CD96 is a leukemic stem cell-specific marker in human acute myeloid leukemia. Proceedings of the National Academy of Sciences of the United States of America. 2007; 104: 11008-11013. doi: 10.1073/pnas.0704271104

19. Hauswirth AW, Florian S, Printz D, Sotlar K, Krauth MT, Fritsch G, Schernthaner GH, Wacheck V, Selzer E, Sperr WR, Valent P. Expression of the target receptor CD33 in CD34+/CD38-/CD123+ AML stem cells. Eur J Clin Invest. 2007; 37: 73-82. doi: 10.1111/j.1365-2362.2007.01746.x

20. Chen Y, Jacamo R, Konopleva M, Garzon R, Croce C, Andreeff M. CXCR4 downregulation of let-7a drives chemoresistance in acute myeloid leukemia. The Journal of Clinical Investigation. 2013; 123: 2395-2407. doi: 10.1172/ JCI66553

21. Sansonetti A, Bourcier S, Durand L, Chomienne C, SmadjaJoffe F, Robert-Lezenes J. CD44 activation enhances acute monoblastic leukemia cell survival via Mcl-1 upregulation. Leukemia Research. 2012; 36: 358-362. doi: 10.1016/j. leukres.2011.09.022

22. Dean M, Fojo T, Bates S. Tumour stem cells and drug resistance. Nat Rev Cancer. 2005; 5: 275-284. doi: 10.1038/ nrc1590

23. Charrad RS, Gadhoum Z, Qi J, Glachant A, Allouche M, Jasmin C, Chomienne C, Smadja-Joffe F. Effects of anti-CD44 monoclonal antibodies on differentiation and apoptosis of human myeloid leukemia cell lines. Blood. 2002; 99: 290-299. doi: 10.1182/blood.V99.1.290

24. Delaunay J, Lecomte N, Bourcier S, Qi J, Gadhoum Z, Durand L, Chomienne C, Robert-Lézénès J, Smadja-Joffe F. Contribution of GM-CSF and IL-8 to the CD44-induced differentiation of acute monoblastic leukemia. Leukemia. 2008; 22: 873-876. doi: 10.1038/sj.leu.2404976

25. Telen MJ, Ferguson DJ. Relationship of Inb antigen to other antigens on $\operatorname{In}(\mathrm{Lu})$-related p80. Vox Sang. 1990; 58: 118 121. doi: 10.1111/j.1423-0410.1990.tb02073.x 
26. Xu Q. The Indian blood group system. Immunohematology. 2011; 27: 89-93.

27. Hopkins S, Jolles S. Drug-induced aseptic meningitis. Expert Opin Drug Saf. 2005; 4: 285-297. doi: 10.1517/14740338.4.2.285

28. Jolles S, Sewell WA, Leighton C. Drug-induced aseptic meningitis: diagnosis and management. Drug Saf. 2000; 22: 215-226. doi: 10.2165/00002018-200022030-00005

29. Orbach H, Katz U, Sherer Y, Shoenfeld Y. Intravenous immunoglobulin: adverse effects and safe administration. Clinical Reviews in Allergy \& Immunology. 2005; 29: 173-184. doi: 10.1385/CRIAI:29:3:173

30. Moris G, Garcia-Monco JC. The challenge of drug-induced aseptic meningitis revisited. JAMA Intern Med. 2014; 174: 1511-1512. doi: 10.1001/jamainternmed.2014.2918
31. Wang JC. Evaluating therapeutic efficacy against cancer stem cells: new challenges posed by a new paradigm. Cell Stem Cell. 2007; 1: 497-501. doi: 10.1016/j. stem.2007.10.005

32. National Comprehensive Cancer Network. (2015). NCCN Clinical Practice Guidelines in Oncology (NCCN Guidelines): Acute Myeloid Leukemia pp. Version 1.2015.

33. Cheson BD, Bennett JM, Kopecky KJ, Buchner T, Willman CL, Estey EH, Schiffer CA, Doehner H, Tallman MS, Lister TA, Lo-Coco F, Willemze R, Biondi A, Hiddemann W, Larson RA, Lowenberg B, et al. Revised recommendations of the International Working Group for Diagnosis, Standardization of Response Criteria, Treatment Outcomes, and Reporting Standards for Therapeutic Trials in Acute Myeloid Leukemia. Journal of Clinical Oncology. 2003; 21: 4642-4649. doi: 10.1200/JCO.2003.04.036 